\title{
Practice and Consideration on Bilingual Teaching in Basic Course-Advanced Mathematics
}

\author{
Xiuqing Yu \\ Department of Mathematics, Dezhou University, Dezhou 253000, Shandong, China \\ Email: sddzyxq@163.com
}

\begin{abstract}
Economic globalization makes bilingual education in universities required. This paper presents to start bilingual education with "Advanced Mathematics" in universities based on analysis of its characteristics. Meanwhile it demonstrates feasibility and necessity on bilingual education in "Advanced Mathematics", also points out existing problems during the process on bilingual teaching and corresponding suggestions.
\end{abstract}

Index Terms - bilingual education, advanced mathematics, problems, suggestion

\section{INTRODUCTION}

Economic globalization makes talent and education international. For current university education, how to cultivate undergrads more international perspective and International competitiveness becomes an important and hot issue in advanced education. At the same time Chinese universities have increasingly recognized Bilingual Education is urgent and significant. How to start, how to push and how to standardize the activity are being explored. In this situation, facing the limited English conditions Chinese university teachers are doing their best to research on bilingual education, and study how to correctly grasp and carry out bilingual education to achieve the goal that students can become international talent after graduating from Chinese university. This paper gives analysis of current resources used in bilingual education in Chinese university including basic knowledge and foreign language level of teachers and students, funds, and so on. Especially it discusses feasibility and necessity on bilingual education in advanced mathematics. What is more, it points out existing problems, meanwhile gives consideration to solve them.

\section{Feasibility and Necessity On Bilingual Education in “AdVANCED Mathematics”}

"Advanced Mathematics" is an important, compulsory, theory basic course for engineering specialty. In the first year, there are six classes a week for the engineering specialty. We suggest and try bilingual education in "Advanced Mathematics" according to teaching content and characteristics of it. Detailed analysis is as following:

Firstly, "advanced mathematics" expands on the content learned in high school. Whether thinking mathematics includes or learning methods it introduces in advanced mathematics are continuation of high school', consequently students are able to accept it naturally with no strangeness and no time to adapt themselves to it. So if we start bilingual education with advanced mathematics learning pressure is relatively small and the effect will be relatively good.

Secondly, "Advanced Mathematics" is a rigorous, strongly logical discipline, and its definitions, theorems, proving and computational process etc. are described in unchanged formats. For example, theorems are often used the form that is "ruguo ... name ... " in Chinese, "if ... then ... " in English. If teachers and students choose the same model several times, not only they can remember it and express other thermos in it smoothly and easily, but also this exercises can improve students' logical thinking ability in English. Furthermore English words relatively appear simple and small for there are a lot of formulas in "Advanced Mathematics", which has bilingual teaching in advanced mathematics more possible.

Thirdly, in the content of "Advanced Mathematics", professional terminology and definitions, theorems come out frequently in a class, such as "limit" in the first and the second chapters is mentioned more than 10 times in a class, and appears one after another in almost 30 classes. In such circumstances choosing "Advanced Mathematics" as the beginning of bilingual education can significantly reduce task to remember English words encountered.

Finally, the main purpose of "advanced mathematics" is to form the necessary mathematical foundations for the follow-up specialty courses. Bilingual Education in "Advanced Mathematics" is a transitional phase, as well as, it is conducive to the full implementation of bilingual education. In summary, all these above indicate that bilingual education in "Advanced Mathematics" is fit to the progressive, cognitive principles, and is feasible and necessary in the first year of university.

Although particular characteristics of "Advanced Mathematics" have bilingual education in it possible, there are many problems for teachers and students to face and conquer in order to carry out it ideally in current condition.

\section{EXISTING PROBLEMS AND CORRESPONDING STRATEGIES ON BILINGUAL EDUCATION}




\section{A. Improve Bilingual Teachers in Quantity and Level through Multi-channel to Resolve Problems at the Lack of} Teachers and Funds.

A competent bilingual teacher involves many aspects, including academic ability, knowledge vision, language skills, and organizational skills. Since teachers in the teaching process play a dominant role in bilingual education, teachers must be equipped with professional knowledge, but also must be proficient in English oral expression ability. But at present there are few teachers in general university who have a good command of professional knowledge and can own oral expressing ability. Not to mention professional teachers who have learned in foreign country. The shortage of bilingual teachers is the most difficulty Chinese universities have to conquer. In the situation that universities have no fund to send professional teachers abroad for learning, Bilingual teachers must do as best as they can to improve their foreign language skills, especially oral and reading skills. When preparing for a class, they need to understand foreign language materials thoroughly, master foreign language professional words encountered and expressions method in foreign language. In the process of bilingual education, teachers must pay special attention to the students' the ability to accept what the teacher teaches, can use simple language to explain complex and difficult mathematics knowledge. Meanwhile, multiple channels to strengthen teachers are required. On the one hand, university should send out specialty teachers to learn to some key universities in which bilingual education is good and hire excellent bilingual teachers. On the other hand, teachers should study each other to develop their bilingual teaching's ability.

\section{B. Continue to Develop Bilingual Teaching Resources to Serve Students.}

During bilingual teaching on "advanced Mathematics", current teaching resources available are limited. Take bilingual textbooks as an example, up to now, there is no special textbook about bilingual teaching in "Advanced Mathematics". Common practice at this stage is to purchase foreign, original, and teaching materials directly. Even if these materials are at the advantage of rich, lively language, supplemented by a large number of cases and task-based exercises, they have different style with Chinese, besides their knowledge structure and the center are not clear enough. Nevertheless Chinese students have used Chinese teaching materials more than ten years, and have been accustomed to finding clearly chapters, sections, reading points. Teachers must spend a lot of time preparing for class according to Chinese students' learning habits, such as combining appropriately the advantage in two kinds of teaching materials, helping students sort out the structure of teaching content and knowledge points. As a result, this will add difficulty to teachers and students. To come out in the tight corner, teachers should gather and do their best to organize an excellent text book and a list of reference books on bilingual education in "advanced mathematics" for students to choose. Moreover the teaching content may be made into courseware lectures and uploaded to the campus network for students and teachers.

\section{Select the Appropriate Teaching Mode and Teaching Methods in Order to Implement Bilingual Teaching Better.}

Engineering majors are generally set up "Advanced Mathematics" course from the freshman year. Students' English level is not good enough to understand what the teacher says if the teacher teaches in English during the whole class. At the beginning, teaching materials should be Chinese, English teaching materials for secondary, teaching language mainly in the mother tongue, English supplemented by. Later on, how much English can be adopted in a class should be based on understanding ability. In addition, teachers can make good use of English Multimedia, which is helpful for students to understand.

\section{Choose Layered Teaching on Bilingual Education in "Advanced Mathematics".}

Usually, each teaching class in "Advanced Mathematics" is formed by more than 100 students in Chinese universities. For the reason that bilingual education commonly slow teaching speed to strengthen communication between teachers and students, bilingual teaching is fit to small classes. Therefore students can be divided into smaller ones by their mathematics grade and English grade, which will be helpful to teaching effect.

\section{E. Establish an Effective Evaluation System on Bilingual Teaching.}

Effective evaluation system can stimulate students to learn more diligently. So teachers should set aside some time for homework and small tests that are required to finish in English in normal times. In the final exam, it is bound to affect the enthusiasm of students on bilingual education if the same test paper is chosen in Chinese classes and bilingual classes. On this account, bilingual classes should be required to do a certain percentage of test questions in a foreign language in examinations, which can test the teaching effect in bilingual language and stimulate students' learning interest.

\section{F. Create a Favorable Bilingual Environment for School.}

Students have learned English from primary school to high school. Although they have paid more effort in the foreign language than other subjects, the effect is not clear, which is due to no good English environment. Students although remember more, they say less, listen less, and use less. Universities should strengthen the overall design to promote campus communication in English between teachers and students. Moreover they can organize students to watch foreign language television programs, listen to foreign language broadcasts, hold essay, speech contest, performances in foreign language and regular foreign language exchange, make use of modern technology to create rich 
learning environment. All above serve to provide a good environment, in which bilingual education and capability of foreign language can promote each other.

\section{G. An Empirical Analysis of Bilingual Education in "Advanced Mathematics".}

98 students in electromechanical specialty enrolled in the experiment about effect on bilingual education, based on their college entrance examination scores in math and foreign language performance. They have been divided into two general classes randomly. One has classes in English, another in Chinese as control experiment. A math teacher with learning experience abroad is in charge of their advanced mathematics course. At the end of a semester the students of the two classes take an examination, which is the same questions with two forms-one is in English, another one in Chinese. The comparison of results is in table one.

TABLE 1

ANALYSIS TABLE OF MATHEMATICS SCORE
\begin{tabular}{|l|l|l|l|l|}
\hline Questions & Single Choice & Calculation questions & Proving questions \\
\hline Average & bilingual class & 76.3 & 79 & 82 \\
\cline { 2 - 6 } & Chinese class & 77.3 & 77.6 & 80.2 \\
\hline
\end{tabular}

We can know bilingual education in "Advanced mathematics" is better in some aspects. In order to learn detailed information about bilingual education from students, Department of mathematics ask the students in bilingual class to answer a questionnaire, which includes ten questions such as whether bilingual teaching add difficulty to understand what teachers teach or not, whether bilingual teaching is helpful to English, etc. The statistics result of questionnaire show: $87 \%$ of students believe that bilingual education is necessary to open, $79 \%$ of students feel that learning math and English have a great role in promoting knowledge, $72 \%$ of students believe that bilingual teaching strengthens learning pressure, meanwhile increases interest to learn, $82 \%$ of students think that bilingual teaching strengthens their self-confidence.

\section{CONCLUSION}

Full implementation of bilingual education in Chinese universities has a lot of problems to resolve. But now there is a good beginning. As the conditions are continuously improved bilingual education will become better and better. Because bilingual education is in Primary stage, professional teachers must constantly make adjustments according to actual situation in practice, and make bilingual teaching more and more perfect. What is more, the goal is early to achieve that train talents who own international perspective and international competitiveness.

\section{REFERENCES}

[1] WANG Li-ping, (2004). Restricting Factors in Bilingual Teaching: a Positivist Analysis and the Solutions. Journal of Yangzhou University (Higher Education Study Edition), 77-80.

[2] LI Chun-mao, WU Yue- feng, LIU Yu. (2007). Research of bilingual teaching progress in China's universities. Journal of Higher Education Management,70-76.

[3] XIA Dan. (2007). Reflections on bilingual education in universities. Journal of Southwest Agricultural University (Social Science Edition), 117-120

[4] WANG You-lian. (2004). Studies on bilingual teaching for undergraduate specialized courses of finance. Journal of University of Shanghai for Science and Technology, 53-56.

[5] FENG Ping. (2009). The exploration and consideration of the bilingual teaching in C Language programming. Journal of Changchun University, 80-82.

[6] HONG Yong-ming. (2007) .Constructing Bilingual Teaching Model Based on the Relations of Different Languages. Journal of Research on Education for Ethnic Minorities.39-44

[7] ZHANG Yu-feng, ZHAO Zhi-xin, etc. Survey of Bilingual Teaching in Clinical Internship of Infectious Diseases. Northwest Medical Education, 108-110.

[8] JIN Ai-juan. (2004). Practice and Consideration on Bilingual Teaching in Major Courses. Journal of Guangdong University of Technology (Social Sciences Edition), 149-151.

[9] He Honggu, Jiang Xiaoying , Xu Weiti. (2004). Practice and Evaluation on Bilingual Teaching for Undergraduate Students in Medicine and Nursing Specialty. Chinese Nursing Research, 440-442.

Xiuqing Yu was born in Dezhou, China in 1968. She received her M.S. degree in mathematics teaching from Shandong University, China in 2007.

She is currently an associate professor in the Department of Mathematics, Dezhou University, Dezhou, China. Her research interests include theory and application of rough system and mathematics teaching. 